\title{
Vivências de felicidade de pessoas idosas
}

\section{Experiences of happiness in elderly people}

\author{
Márcia Maria Carvalho LUZ \\ Mauro Martins AMATUZZI'
}

\begin{abstract}
Resumo
O estudo consistiu em uma pesquisa exploratória junto a pessoas idosas, com o objetivo de conhecer e descrever os aspectos emocionais e cognitivos de suas vivências de felicidade. Tendo em vista o aumento da longevidade, várias pesquisas vêm sendo realizadas a respeito da qualidade de vida na velhice, bem-estar e envelhecimento satisfatório. O termo envelhecimento bem sucedido vem despertando o interesse de vários pesquisadores, pois a visão de velhice infeliz precisa ser desmistificada, dando lugar a uma concepção mais positiva com relação a essa fase da vida. Participaram deste estudo três idosos, não-institucionalizados, sendo dois do sexo feminino e um do sexo masculino. Constatou-se, por meio da análise fenomenológica, que seus momentos de felicidade estão relacionados ao contato familiar e social, à autonomia e à capacidade para trabalhar, proporcionando sentimento de valor pessoal, auto-estima e bem-estar.
\end{abstract}

Unitermos: Envelhecimento. Felicidade. Qualidade de vida.

\begin{abstract}
The present study consists of exploratory research involving the elderly, with the objective of understanding and describing the emotional and cognitive aspects of their experiences of happiness. In view of the increase in longevity, several research studies have been carried out with regard to the quality of life in old age, well-being and satisfactory aging. The concept of successful aging has been arousing the interest of a number of researchers, as the perception of unhappiness in old age needs to be demystified, opening the way for a more positive interpretation of this stage of life. Participating in this study were three old people, not institutionalized, 2 females and 1 male. It was found, by means of phenomenological analysis, that their moments of happiness are related to family and social contact, to being independent and having the capacity to work, providing them with a feeling of personal value, self-esteem and well-being.
\end{abstract}

Uniterms: Aging. Happiness. Quality of life.

Em 1900, apenas 1,0\% da população tinha idade superior a 65 anos; entretanto, hoje este número atinge $6,2 \%$. Acredita-se que, no ano de 2050, os idosos serão um quinto da população mundial. Este número acentuado traz grandes conseqüências para a sociedade. Portanto, há necessidade de se buscar conhecer os determinantes para melhores condições de vida, bem como as diferentes faces que envolvem o processo de envelhecimento (Netto \& Ponte, 2002).

Nos estudos sobre o processo de envelhecer se encontram, com freqüência, mais referências aos aspectos negativos (perdas e doenças) do que comentários sobre os ganhos associados à velhice (sabedoria, experiência e habilidade nos relacionamentos sociais).

$\cos$

1 Pontifícia Universidade Católica de Campinas, Centro de Ciências da Vida, Programa de Pós-Graduação em Psicologia. Campus II, Av. John Boyd Dunlop, s/n., Jd. Ipaussurama, 13060-904, Campinas, SP, Brasil. Correspondência para/Correspondence to: M.M.C. LUZ. E-mail: <marciamcluz@yahoo.com.br>. 
Isso se deve à crença de que as perdas só ocorrem na velhice e de que os ganhos estão restritos às fases iniciais do desenvolvimento. Porém, perdas e ganhos ocorrem em todas as etapas da vida, embora na velhice haja mais perdas do que ganhos (Freire \& Resende, 2001).

Envelhecimento não implica necessariamente em doença e afastamento. $\mathrm{O}$ idoso tem potencial para mudar as situações de sua vida e a si mesmo, e tem muitas reservas inexploradas. Os idosos podem se sentir felizes, realizados e atuantes em seu meio social. Muitos estudiosos de diversas áreas, e as pessoas, de um modo geral, têm-se interessado por buscar formas de se chegar a um envelhecimento bem-sucedido e satisfatório (Freire, 2000).

O termo envelhecimento bem-sucedido apareceu na Gerontologia nos anos 60, associado a uma importante mudança ideológica, que consistiu em considerar que a velhice e o envelhecimento não são sinônimos de doença, inatividade ou uma retração geral do desenvolvimento humano. Desde então, a Gerontologia passou a investigar também os aspectos positivos da velhice, o potencial para desenvolvimento e, principalmente, a heterogeneidade associada a este processo (Neri, 2003).

Desde o dia em que nascemos, estamos em contato com muitas pessoas. Passamos por muitos grupos e desempenhamos diversos papéis sociais. Isso nos faz sentir pertencentes a algo, a alguém, ter importância ao desempenhar este ou aquele papel. Além do aspecto da convivência social, outro importante é a estimulação do pensar, do fazer, do discutir e do aprender. O desempenho de atividades e o contato social podem contribuir para o reforço do sentimento de valor pessoal, do autoconceito e da auto-eficácia, facilitando a adaptação do idoso às suas perdas (Deps, 2003; Zimerman, 2000).

É importante reconhecer, no idoso, o seu papel mediador na vida social, nos diversos tempos e espaços. Partindo deste princípio, a velhice constitui um tempo estratégico da vida em sociedade. Porém, o que a velhice representa está em nós e na imagem que construímos (Gusmão, 2001).

Para Sad (2001), maturidade inclui autoconhecimento e auto-aceitação, e é uma qualidade do self construída ao longo de toda a vida. Durante a velhice, há um processo de busca interior e de investimento na espiritualidade e no autoconhecimento, componentes essenciais para o desenvolvimento pessoal.
A religião, a ciência, a arte, a filosofia, a natureza, a educação e a literatura são caminhos para se chegar a uma transformação pessoal. É a partir desse princípio que a vida de uma pessoa idosa pode vir a ser de grande riqueza interior em relação ao encontro com o próprio self, com sua essência. Então, com um maior conhecimento, pode-se exercitar o corpo e a mente até chegar à plenitude de capacidades e cultivar modos mais livres e positivos de ser, características que permitem uma melhor apreciação das dimensões da vida humana (Sad, 2001). Este estudo teve como objetivo conhecer e descrever, em seus aspectos cognitivos e emocionais, vivências de felicidade de pessoas idosas.

\section{Método}

Tratou-se de uma pesquisa exploratória, buscando uma compreensão do fenômeno das vivências de felicidade na velhice e uma aproximação do vivido com o significado nele contido.

\section{Participantes}

Foram entrevistados três idosos não-institucionalizados: um deles era do sexo masculino, comerciante, com idade de 65 anos; os outros dois eram do sexo feminino, sendo que uma era vigia de uma escola, com idade de 60 anos, e a outra era comerciante, com 59 anos. Os três participantes residiam em uma cidade do interior de São Paulo. Todos os depoimentos foram colhidos no ambiente de trabalho dos participantes. Foi utilizado um gravador para a coleta dos dados, mediante o consentimento do entrevistado.

\section{Instrumento}

Foi feita uma entrevista não diretiva que, segundo Mucchielli (1998), tem a finalidade de compreender o outro em sua própria língua, de pensar em seus termos e de descobrir seu universo subjetivo, buscando as significações que a situação tem para o entrevistado.

\section{Procedimentos}

Primeiramente, a pesquisadora buscou apreender os conceitos que envolvem o envelhecimento bem sucedido. Desenvolveu um estudo que, após aprovação 
pelo Comitê de Ética em Pesquisa, teve como primeiro passo entrar em contato com uma pessoa conhecida da pesquisadora, solicitando que indicasse voluntários que se enquadrassem nos critérios estabelecidos para a pesquisa, e que se dispusessem a participar, cientes dos objetivos desta. Em um segundo momento, os voluntários foram contatados pessoalmente pela pesquisadora. A primeira participante marcou a entrevista para a semana seguinte; já os outros dois aceitaram dar seu depoimento logo no primeiro contato. Após a leitura do Termo de Consentimento Livre e Esclarecido, o gravador foi ligado e a questão desencadeadora foi dita: "Estou fazendo uma pesquisa sobre vivências de felicidade compessoas da terceiraidade. Vocêpoderia me contarsuas vivências defelicidade?".

Após a coleta dos depoimentos, a primeira etapa foi a sua transcrição para o papel. Em seguida, foram feitas as pontuações necessárias, de forma a tornar o texto compreensível, porém, sem distorções de sentido. Depois, foi feita a análise fenomenológica proposta por Forghieri (1993) em cada depoimento. Finalmente, as três sínteses foram comparadas, buscando-se pontos em comum, que foram mencionados como importantes para a felicidade.

Analisando as entrevistas dos três depoentes em relação às suas vivências de felicidade, encontrou-se nelas alguns aspectos comuns, tais como a importância da família e do trabalho. Os três participantes mencionaram a família como o elemento principal de suas vidas, como a razão de viver e a principal fonte de felicidade. O trabalho foi citado como sendo um prazer; para eles, o fato de trabalhar tem conotação prazerosa, e não de obrigação (ou tediosa). A felicidade foi destacada como estando presente no cotidiano. Explicou a terceira participante, casada, 59 anos:

A felicidadeéum sentimento simples. Elaéconstruída no dia-a-dia. Tem gente que não vê a felicidade. Felicidade nãoéter dinheiro, ter de tudo. Eu me considero feliz porter minha mãe viva ainda, com 90 anos. Eu me considero feliz por ter amigos e por trabalhar.... A felicidade estánas pequenas coisas, ela é um sentimento simples que as pessoas muitas vezes não percebem.... Afelicidade éum momento. Tão simples, que você pode passar por ela e não perceber. Afelicidade seresumenisso, na simplicidade de cada momento no dia-a-dia das pessoas.

O primeiro participante, casado, 65 anos, enfatizou as relações sociais e de amizade. Para ele, a felicidade é uma vivência diária. Possui grande interesse por atividades; dessa maneira, procura estar sempre aprendendo coisas novas e se divertindo, mantendo o contato social. Ele comentou:

Felicidade é uma vida tranqüila, tudo bem, tudo em harmonia, muita paz, muito amor com a família, com os netos... . A família é muito importante. Um momento de felicidade meu é quando estou com meus netos. $O$ lazer com meus netos. Quando a gente sai, vai à praça. Eu também freqüento clube com a minha esposa... . Eu saio sábado, domingo. Converso com os amigos. Eu acho muito importante estar integrado na sociedade. Eu tenho um grupo de amigos muito bons. A gente tem aulas de dança, aulas de pintura. Estou fazendo amizades com pessoas quejamais eu iria.

A segunda participante, casada, 60 anos, deu graças a Deus várias vezes durante seu depoimento, mostrando que sua fé é uma fonte de felicidade e de apoio para que ela possa ter confiança e firmeza para lutar contra os obstáculos da vida. Outro ponto é sua sensação de "missão cumprida", ao olhar para seu passado e ver tudo o que conquistou ao longo de sua existência. Ela afirmou: "Eu tive mais situações difíceis... e mesmo assim hoje eu me considero uma pessoa feliz, realizada... eu acho que fiz tudo o que uma mulher tem que fazer. Sevocê tem féem Deus, vocêfaz tudo, você não tem momentos de desespero que o povo tem".

Compreendeu-se, desse modo, que as vivências de felicidade destes participantes estão relacionadas ao bem-estar de sua família e ao fato de poderem trabalhar, sendo o trabalho não um sustento, apenas, mas uma fonte de prazer, por se sentirem ativos. Constatou-se também a importância da fé, das relações sociais e de amizade. De acordo com os participantes desta pesquisa, a felicidade pode ser um sentimento simples inserido na vida diária, mas ela também pode ser uma satisfação em olhar para trás e ver uma vida de conquistas, e ter pensamentos positivos para o futuro.

\section{Resultados e Discussão}

Os resultados obtidos neste estudo revelaram que existem muitos pontos em comum, em relação à experiência de felicidade, para os participantes desta pesquisa. Todavia, estes idosos estão em atividade, o que difere da condição de passividade em que muitos 
se encontram atualmente. Os depoimentos revelaram que o envelhecimento pode ser vivido de forma positiva. Entretanto, é necessária qualidade de vida. A qualidade de vida é considerada, de acordo com Rolim e Forti (2004), uma condição para que haja um enveIhecimento bem-sucedido.

O idoso possui a capacidade de ajustar seus projetos de vida segundo suas condições presentes. Portanto, a satisfação com a vida se mantém elevada quando há empenho para o alcance de metas significativas na manutenção ou restabelecimento do seu bem-estar (Freire, 2000).

Nota-se, no primeiro participante, uma busca por aprendizado e atividades, porém estas estão de acordo com suas condições de vida, o que possibilita satisfação e bem-estar. Para Zimerman (2000), é importante buscar a própria felicidade, ter objetivos, projetos e continuar aproveitando a vida, pois isso proporciona uma vida saudável na velhice, com autonomia e indeendência.

Segundo Neri (2001) e Baldessin (2002), a velhice é um "estado de espírito", pois não depende da idade cronológica ou de outros marcadores de velhice. Dessa maneira, o envelhecimento pode ser dividido em físico e espiritual. No caso do primeiro participante, embora ele tenha idade e aparência envelhecida, nota-se que seu espírito continua preservado, transmitindo vitalidade e busca por conhecimento.

Para Zimerman (2000) e Deps (2003), além da convivência, o pensar, o fazer e o aprender são fundamentais. $\bigcirc$ desempenho de atividades e o suporte social são reforços ao sentimento de valor pessoal, autoconceito e auto-eficácia. Possivelmente, o fato de os participantes terem enfatizado a importância do trabalho relaciona-se a este pressuposto descrito pelas autoras; e a integração social, juntamente com o reconhecimento de colaboração e participação possibilitado pelo trabalho, serve como reforço para que o idoso sinta-se bem consigo mesmo.

Muitos idosos enfrentam circunstâncias de vida não favoráveis à expressão de felicidade; tais como: privação econômica, isolamento social, perda de amigos, doenças crônicas e a falta de recursos para uma vida ativa e saudável. Segundo Deps (2003), para que a 306 atividade seja um momento prazeroso e tenha resulta- dos positivos, como a satisfação pessoal, deve-se levar em conta a motivação e as circunstâncias na qual surgiu.

No caso do primeiro participante, há grande motivação para o desempenho de suas atividades. Ele possui clareza de que estas fazem bem, e dá ênfase à interação social que surge a partir delas; sendo que os amigos são reforçadores para que ele continue motivado e amplie cada vez mais sua rede de amizades.

Em relação à família, observou-se que ela é de grande importância para os participantes. Segundo Boutique e Santos (2002), a família é a raiz da estrutura social e, na velhice, torna-se fonte de estabilidade e de proteção, havendo maior dependência do idoso para com sua família.

A interação familiar é vital para o bem-estar do idoso, já que ele se insere neste sistema. A família deve ajudar o idoso a viver melhor, não como um peso, mas como integrante do sistema familiar. Andolfi (apud Zimerman, 2000) define: "A família é um sistema ativo em constante transformação, ou seja, um organismo complexo que se altera com o passar do tempo para assegurar a continuidade e o crescimento de seus componentes" (p.53).

Verifica-se uma grande importância da família para o idoso, pois, como integrante do sistema familiar, ele é influenciado por esta dinâmica e, quando ela não caminha em harmonia, não há promoção de bem-estar para ele. Nos depoimentos, observa-se a importância da família, mas isto ocorre porque há um clima familiar favorável, produtor de bem-estar e de qualidade de vida. A ligação entre o idoso e seus familiares é forte, e há maior valorização dos filhos e dos netos por parte dele, que se sente realizado ao vê-los em harmonia e ao saber que se trata da "sua família".

Na terceira idade, assim como em outras fases da vida, a família tem posição de destaque. Ela vai se alterando à medida que seus membros envelhecem, principalmente no que diz respeito aos papéis familiares (Zimerman, 2000).

Maturidade inclui autoconhecimento e auto-aceitação. Na velhice, há um processo de busca interior e de investimento na espiritualidade e no autoconhecimento, resultando em desenvolvimento pessoal. A vida de uma pessoa idosa pode vir a ser de grande riqueza interior, no que concerne ao encontro com sua 
própria essência. Dessa forma, pode-se chegar à plenitude, com modos mais positivos de ser e apreciação da vida (Sad, 2001).

A segunda participante tem a religião como fonte de felicidade. Ela aprecia a vida e mostra-se satisfeita com a mesma. Sua espiritualidade transmite-lhe sentimentos positivos e Ihe dá força para continuar lutando e superando obstáculos.

Vários estudos sugerem que a espiritualidade pode servir como fator de proteção, podendo influenciar a vida da pessoa por meio de emoções positivas. Nesse sentido, a afirmação de Sad (2001) confirma-se no depoimento da segunda participante, que tem a espiritualidade como parte de sua vida. Ela possui uma satisfação e sensação de "missão cumprida", devido ao fato de fazer uma revisão dos acontecimentos de sua história e ver o valor de toda uma existência, levando-a à auto-aceitação.

Os depoimentos apontaram o bem-estar subjetivo na idade madura relacionado aos vínculos positivos com os outros, auto-aceitação, boa qualidade de vida, capacitação para o trabalho, otimismo e autonomia.

\section{Considerações Finais}

Os resultados obtidos por meio dos três depoimentos permitiram compreender que pessoas otimistas e que possuem eventos genético-biológicos, sócio-históricos e psicológicos adequados se adaptam melhor às transformações trazidas pelo envelhecimento, ou seja, há um equilíbrio entre as perdas e os ganhos, o que proporciona bem-estar e felicidade.

Constatou-se que a dimensão familiar e a dimensão laboral possuem grande importância, sendo fontes de felicidade. Verificou-se que a velhice pode ser um período prazeroso, com projetos e realizações. Embora esteja diretamente ligada à qualidade de vida, a velhice pode ser um período de liberdade e de experiência acumulada, ocasionando maior grau de especialização e capacitação, com o desenvolvimento de projetos de vida e de potencialidades.

\section{Referências}

Baldessin, A. (2002). O idoso: viver e morrer com dignidade. In M. P. Netto. Gerontologia: a velhice e o envelhecimento em visão globalizada. São Paulo: Atheneu.

Boutique, N. C., \& Santos, R. L. A. (2002). Aspectos socioeconômicos do envelhecimento. In M. P. Netto. Gerontologia: a velhice e o envelhecimento em visão globalizada. São Paulo: Atheneu.

Deps, V. L. (2003). Atividade e bem-estar psicológico na maturidade. In A. L. Neri. Qualidade devida eidade madura (5a. ed.). São Paulo: Papirus.

Forghieri, Y. C. (1993). Psicologia fenomenológica: fundamentos, método e pesquisas. São Paulo: Pioneira.

Freire, S. A. (2000). Envelhecimento bem sucedido e bem-estar psicológico. In A. L. Neri \& S. A. Freire. E por falar em boa velhice. São Paulo: Papirus.

Freire, S. A., \& Resende, M. C. (2001). Sentido de vida e envelhecimento. In A. L. Neri. Maturidade e velhice: trajetórias individuais e socioculturais. São Paulo: Papirus.

Gusmão, N. M. M. (2001). A maturidade e a velhice: um olhar antropológico. In A. L. Neri. Desenvolvimento e envelhecimento: perspectives biológicas, psicológicas esociológicas. São Paulo: Papirus.

Mucchielli, R. (1998). A entrevista não diretiva. São Paulo: Martins Fontes.

Neri, A. L. (2001). Maturidade e velhice: trajetórias individuais e socioculturais. São Paulo: Papirus.

Neri, A. L. (2003). Qualidade de vida no adulto maduro: interpretações teóricas e evidências de pesquisa. In A. L. Neri. Qualidade de vida e idade madura (5a. ed.) São Paulo: Papirus.

Netto, M. P., \& Ponte, J. R. (2002). Envelhecimento: desafio na transição do século. In M. P. Netto. Gerontologia: a velhice e o envelhecimento em visão globalizada. São Paulo: Atheneu.

Rolim, F. S., \& Forti, V. A. M. (2004). Envelhecimento e atividade física auxiliando na melhoria e manutenção da qualidade de vida. In M. J. D. Diogo, A L. Neri \& M. Cachioni. Saúde e qualidade de vida na velhice. Campinas: Alínea.

Sad, I. (2001). Revisão de vida, autoconhecimento e autoaceitação: tarefas da maturidade. In A. L. Neri. Desenvolvimento e envelhecimento: perspectivas biológicas, psicológicas e sociológicas. São Paulo: Papirus.

Zimerman, G. I. (2000). Velhice: aspectos biopsicossociais. Porto Alegre: ArtMed.

Recebido em: 6/12/2005

Versão final reapresentada em: 12/9/2006

Aprovado em: 18/7/2007 